\title{
EIXOS COMERCIAIS EM ANÁPOLIS (GO): ESTUDO DE CASO DAS ATIVIDADES PRESENTES NAS PRINCIPAIS VIAS DA ÁREA NORDESTE DA CIDADE
}

\author{
Bruno Augusto de Souza ${ }^{1}$ \\ Janes Socorro da Luz ${ }^{2}$
}

\begin{abstract}
Resumo: Este trabalho aborda as questões referentes à construção do espaço urbano, suas formas e os agentes que o modificam ao longo do tempo. Anápolis (GO) é uma cidade média que exerce influência regionalmente, conta com 370.875 habitantes, segundo dados do IBGE, possui forte atividade comercial e industrial. Para este estudo, utilizamos os eixos comerciais da área nordeste da cidade que é composta por 13 bairros situados na área de influência de duas rodovias federais, a BR-153 e a BR-414. Caracteriza-se por ser uma área de expansão recente, pois três loteamentos foram aprovados nas primeiras décadas do século XXI. As atividades presentes foram caracterizadas e georreferenciadas ao longo dos principais eixos comerciais identificados na área, demonstrando a atratividade que essa parte da cidade exerce sobre o processo de expansão urbana recente que a cidade de Anápolis apresenta.
\end{abstract}

Palavras-chave: Cidade; Espaço Urbano; Eixos Comerciais; Expansão Urbana

\section{COMMERCIAL AXES IN ANAPOLIS (GO): CASE STUDY OF THE ACTIVITIES IN THE MAIN ROADS FROM NORTHEAST AREA OF THE CITY}

\begin{abstract}
This paper discusses issues relating to the construction of urban space, its forms and agents that modify it over time. Anapolis (GO) is a medium-sized city that has influence regionally, has 370.875 inhabitants, according to the Brazilian Institute of Geography and Statistics, has strong business and industrial activity. For this study, we used the commercial axis of the northeast area of the city which is composed of 13 districts located in the catchment area of two federal highways, BR-153 and BR-414. It's characterized by being an area of recent expansion, as three subdivisions were approved in the first decades of the twenty-first century. The present activities were characterized and georeferenced along major trade routes identified in the area, demonstrating the attractiveness that this town has on the process of urban sprawl recent than the city of Anapolis presents.
\end{abstract}

Keywords: City; Urban Space; Commercial Axes; Urban Expansion

\section{EJES COMERCIALES EN ANÁPOLIS (GO): ESTUDIO DE CASO DE LAS ACTIVIDADES PRESENTES EN LAS PRINCIPALES VÍAS DEL ÁREA NORESTE DE LA CIUDAD}

Resumen: Este trabajo aborda cuestiones de la construcción del espacio urbano, sus formas y los agentes que lo modifican a lo largo del tiempo. Anápolis (GO) es una ciudad media que ejerce influencia regionalmente, cuenta con 370.875 habitantes, según datos del IBGE, posee

\footnotetext{
${ }^{1}$ Doutorando em Geografia pelo Instituto de Estudos Socioambientais (IESA) da Universidade Federal de Goiás (UFG). Bolsista da Coordenação de Aperfeiçoamento de Pessoal de Nível Superior (CAPES). b.a.desouza@hotmail.com

${ }^{2}$ Doutora em Geografia pela Universidade Federal de Uberlândia (UFU). Professora do Programa de Pósgraduação Stricto Sensu em Ciências Sociais e Humanidades: Territórios e Expressões Culturais no Cerrado (TECCER) da Universidade Estadual de Goiás (UEG).jnsluz@ hotmail.com
} 
fuerte actividad comercial e industrial. Para este estudio, utilizamos los ejes comerciales del área noreste de la ciudad que está compuesta por 13 barrios situados en el área de influencia de dos carreteras federales, la BR-153 y la BR-414. Se caracteriza por ser un área de expansión reciente, pues, tres loteamientos fueron aprobados en las primeras décadas del siglo XXI. Las actividades presentes fueron caracterizadas y georreferenciadas a lo largo de los principales ejes comerciales identificados en el área, demostrando la atracción que esa parte de la ciudad ejerce sobre el proceso de expansión urbana reciente que la ciudad presenta.

Palabras clave: Ciudad; Espacio Urbano; Ejes Comerciales; Expansión Urbana

\section{INTRODUÇÃO}

Esse estudo aborda questões referentes à produção do espaço urbano em Anápolis (GO) com foco na área nordeste da cidade. Com três novos loteamentos aprovados na primeira década do século XXI, o estudo dessa área se torna importante, visto que compreende uma área de expansão acelerada na cidade.

O embasamento teórico analisa a discussão de Carlos (2007, 2011), Corrêa (1995, 2007), Lefebvre (2001), Luz (2009), Santos (1994), Souza (2009), e Sposito (2005, 2007).

Utilizamos o método dialético como direção e o estudo de caso como o tipo de pesquisa, pois, além de demonstrar as atividades que são atrativas para o não isolamento do local, apresentamos os elementos de infraestrutura presentes no mesmo.

As principais questões que motivaram a pesquisa tratam da influência atrativa do local, como por exemplo: Quando os bairros da área nordeste de Anápolis surgiram? O desenvolvimento da atividade comercial e de serviços na área nordeste significa a formação de um subcentro na cidade de Anápolis (GO)? Como caracterizar o processo de centralização exercido pelas atividades terciárias na área nordeste? Existem atividades que se destacam? São atividades típicas das áreas centrais ou periféricas? Há conexão da localização próxima da área nordeste com a expansão acelerada em seus arredores?

Ao considerar esses questionamentos, traçamos o objetivo geral desse estudo que é o de compreender o processo de descentralização da área nordeste da cidade de Anápolis (GO). Os objetivos específicos são: Destacar a formação da área nordeste; descrever as atividades localizadas nos bairros, como a diferenciação de serviços que estão principalmente, na Avenida do Estado e Avenida 25; analisar a importância que o não isolamento da área nordeste exerce na expansão acelerada nos bairros aprovados no século XXI.

Realizamos trabalhos de campo para georreferenciar a área total dos bairros, coletamos as localizações das atividades presentes na área nordeste por meio de aparelho GPS, realizamos análises com os dados obtidos por meio do geoprocessamento ao 
confeccionar mapas temáticos no software ArcGIS, obtivemos e analisamos dados do setor de cadastro imobiliário da Secretaria de Obras, Serviços Urbanos e Habitação da Prefeitura Municipal de Anápolis referentes aos bairros da área nordeste.

\section{Processos e formas espaciais na produção do espaço urbano}

No espaço geográfico, as dinâmicas ao longo do tempo impostas modificam o entendimento e a configuração dos territórios. Desde a constituição de pequenos vilarejos até o alvorecer das metrópoles, diversos processos estão imbricados para subsidiar a formação desses locais, esses procedimentos se configuram complexos e relacionados. Geram-se então as necessidades de estudo para análise dessas constituições.

As cidades são fragmentadas em seu processo dinâmico de construção. A infraestrutura que alguns locais possuem, outros não, deixam os moradores a mercê de graves problemas. Santos (1994, p. 95) afirma a respeito da urbanização corporativa, que a cidade:

[...] é, empreendida sob o comando dos interesses das grandes firmas, constitui um receptáculo das conseqüências de uma expansão capitalista devorantes dos recursos públicos, uma vez que estes são orientados para os investimentos econômicos, em detrimento dos gastos sociais.

Com essa afirmação, vê-se que os bairros existentes na cidade compreendem diferentes formas, ora são dotados de infraestrutura, atividades diversificadas e equipamentos, ora demoram alguns anos para se instalarem. As cidades médias devem ser analisadas de forma diferenciada, pois suas características variam conforme sua localização e dinâmica regional apresentada.

Encontramos cidades médias que representam importantes centros do comércio e serviços, como as que constituem centros de referência do agronegócio. De acordo com Corrêa $(2007$, p. 23), "[...] trata-se de discutir uma expressão vaga, [...] e impregnada do idealismo que a concebe como um ideal a ser alcançado, apresentando as vantagens da pequena cidade sem ter, contudo, as desvantagens das grandes".

Em aspectos funcionais, Sposito et al. (2007, p. 48) caracterizam os perfis de atração das cidades médias: "[...] pelo enfoque funcional, sempre esteve associada à definição de seus papéis regionais e ao potencial de comunicação e articulação proporcionado por suas situações geográficas".

As formas espaciais se desenvolvem em uma cidade por influência da acumulação capitalista, a constituição de diferentes formas e funções ao longo do tempo, moldam-na de 
acordo com tais interesses. Inclusive, conforme Corrêa (1995, p. 37), existe os seguintes processos espaciais e suas respectivas formas:
a) centralização e a área central;
b) descentralização e os núcleos secundários;
c) coesão e as áreas especializadas;
d) segregação e as áreas sociais;
e) dinâmica espacial da segregação;
f) inércia e as áreas cristalizadas.

Lefebvre (2001, p. 54) afirma que as "formas, estruturas, funções urbanas (na cidade, nas relações da cidade com o território influenciado ou gerido por ela, nas relações com a sociedade e o Estado) agiram umas sobre as outras e se modificaram". Nesse sentido, percebe-se que a interconexão entre forma e função contribui para dinamizar a produção do espaço urbano e estabelecer ligações entre as diferentes partes que o constituem.

A respeito da centralização e sua área central, Corrêa (1995, p. 38) afirma que "a cidade mantém uma série de ligações com o mundo exterior a ela, ligações que envolvem fluxos de capitais, mercadorias, pessoas e ideias. Para isto ela é um foco de transportes interregionais". Mantenedora dos fluxos de pessoas e com isso ideias dos mais variados tipos e de capitais, a área central se mostra como a área core de uma cidade.

O outro segmento da área central que é a zona periférica do centro possui as seguintes características: $\mathrm{O}$ solo de uso semi-intensivo como comércio atacadista, armazenagem e estacionamentos. Ao contrário do núcleo central, nesse segmento há a presença forte de escala horizontal. Limitado crescimento horizontal, devido a uma restrição locacional e instalações em outros lugares, com preços reduzidos do solo. Constitui-se em uma área de baixo status social, fato que as residências são de baixa classe média e sua grande maioria se encontra deteriorada. É foco de transportes inter-regionais, com a instalação de terminais ferroviários e rodoviários (CORRÊA, 1995).

Ao verificar o alto preço do solo, a restrição ao crescimento horizontal, compreende-se a formação de descentralizações quando a cidade se expande, de forma acelerada ou não. Esse processo cria maior constituição de atividades ao longo dos diversos bairros com uma considerável distância da área central, e facilita a vida dos habitantes que ali estão.

A descentralização não surge em qualquer área da cidade, mas em locais que possuem infraestrutura, facilidade de transportes, lotes não ocupados a baixos preços e outros fatores positivos para sua implementação. A alocação de serviços nessas áreas se estabelece devido à demanda local, quando há o crescimento demográfico e com retorno financeiro. 
Para a afirmação da constituição de novas centralidades, Sposito (2005, p. 97) afirma que:

As áreas centrais estão se multiplicando e a observação dessa tendência pode ser reconhecida como resultado de uma lógica que passou a orientar a constante dinâmica de reestruturação das cidades brasileiras. A multiplicação de áreas de concentração de atividades comerciais e de serviços revela-se através de nova espacialização urbana [...], o reconhecimento da multiplicação de áreas centrais de diferentes importâncias e papéis funcionais pode se dar através da observação da localização das atividades comerciais e de serviços.

Ao analisar as afirmações de constituição da descentralização, compreendemos que a ocorrência dela conclui a formação de novas centralidades ou eixos comerciais em outros pontos da cidade. Ao ocorrer a descentralização de atividades na área central da cidade, a ocorrência desse processo tem algum objetivo específico, seja aumentar a produtividade, o lucro, ou mesmo devido ao alto preço da terra compreendida na área central.

Com a expansão do espaço urbano da cidade, as novas centralidades e os eixos comerciais facilitam a vida dos habitantes que ali estão. Evitam-se transtornos gerados por longos deslocamentos, economia de dinheiro em locomoção, tanto no uso de transportes coletivos, como na economia de combustíveis de transporte particular. Economia de tempo é outro fato observado com serviços próximos na região.

\section{A ação dos agentes na produção do espaço urbano}

Na lógica capitalista de construção do espaço urbano, Corrêa (1995, p. 12) aponta os seguintes agentes, responsáveis pela dinâmica socioespacial vigente:

\footnotetext{
a) os proprietários dos meios de produção, sobretudo os grandes industriais;

b) os proprietários fundiários;

c) os promotores imobiliários;

d) o Estado; e

e) os grupos sociais excluídos.
}

Cada agente tem sua parcela de regulação na imposição sistemática de ajuste, os interesses desses agentes se imprimem na capacidade de empreendedorismo e seus empenhos para a construção dinâmica da cidade a seu favor.

Ao considerar esses agentes, Corrêa (1995) afirma que as estratégias dos mesmos estão inter-relacionadas na ação regulatória do espaço urbano. A começar pelos proprietários dos meios de produção, os mesmos necessitam de grande espaço para a implantação de suas empresas, boa acessibilidade e menor preço na terra para obterem aspectos positivos locacionais e lucro. 
Os proprietários fundiários são os detentores de terras e que visam a expansão urbana. Tendem a prática da conversão de terra rural em urbana, a última é mais valorizada que a rural. Estão interessados no valor de troca da terra e não em seu valor de uso (CORRÊA, 1995).

Os promotores imobiliários estão ligados à incorporação, que significa a operação-chave da promoção imobiliária; o financiamento para se investir na compra do terreno e construção do imóvel; ao estudo técnico, que verifica a viabilidade da obra dentro das normas; a construção ou produção física do imóvel; e a comercialização ou transformação do capital-mercado em capital-dinheiro, por meio de propagandas (CORRÊA, 1995).

O Estado se liga a organização dinâmica do espaço urbano de maneira complexa. O mesmo pode se configurar como grande industrial, consumidor de espaço e de localizações específicas, proprietário fundiário e promotor imobiliário, na implantação de serviços públicos como o sistema viário, calçamento, água, esgoto, iluminação, coleta de lixo dentre outros fatores, e se espera essas ações desse agente (CORRÊA, 1995). A ação do Estado na dinâmica urbana privilegia em grande parte os interesses da classe dominante e, também, deve se considerar que essa ação se faz em três níveis político-administrativos e espaciais: federal, estadual e municipal.

E os grupos sociais excluídos se compreendem pela disparidade existente no sistema capitalista, que causa mazelas em grande parte da população como subnutrição, desemprego, empregos mal remunerados, doenças, baixo nível de escolaridade. Não possuem renda suficiente para adquirirem um imóvel decente ou mesmo pagar aluguel (CORRÊA, 1995).

\section{Breve histórico de Anápolis (GO) e os eixos comerciais da área nordeste da cidade}

O município de Anápolis está localizado no estado de Goiás, posicionado na mesorregião do Centro Goiano, onde se constitui na cidade polo da microrregião que recebe o nome da cidade (ver Mapa 01). 


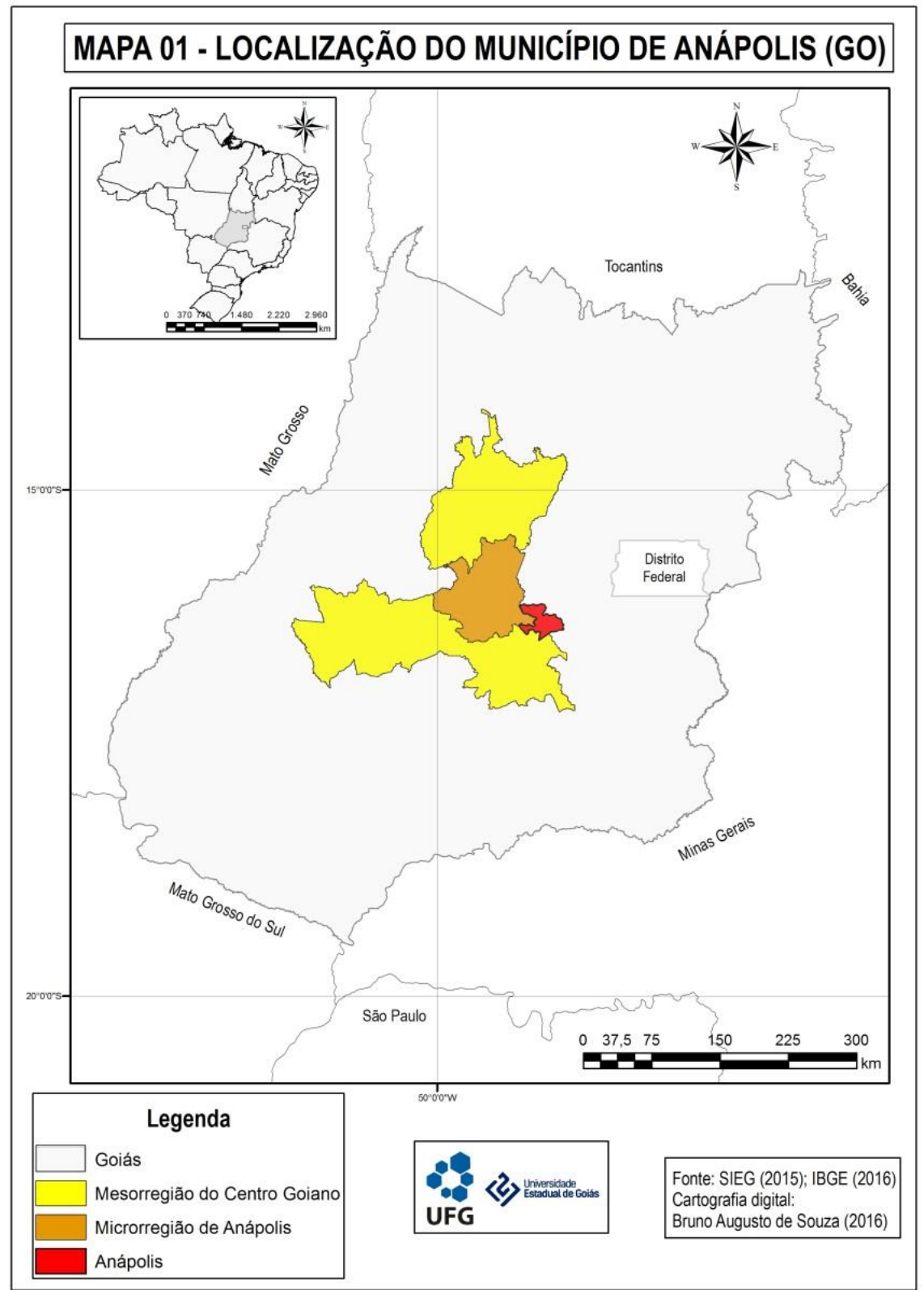

Os primeiros momentos do povoado que surgiu na região que hoje compreende o município de Anápolis apresentam duas explicações: Uma delas foi por motivação religiosa; e a outra, por causa das condições naturais favoráveis do terreno.

A primeira explicação de acordo com França (1974) foi que na região que estava a cabeceira do córrego das Antas, fronteira entre os territórios de Meiaponte e Bonfim, existia uma concentração populacional composta por pequenos comerciantes e fazendeiros locais. Estes comemoravam anualmente no dia 26 de julho na casa de Manoel Rodrigues da Silva, o dia em consagração a Nossa Senhora Santana.

De acordo com França (1974, p. 638): "Em 1870, aqueles fazendeiros doaram uma área de terras à santa, desejosos de que nela se construisse [sic] uma capela em seu louvor". E a autora acrescenta que "no mesmo ano da doação, Gomes de Souza Ramos 
transferiu-se de Bonfim para o local, que já contava com sete casas, iniciando em 1871 a construção da capela" (IDEM, 1974, p. 638).

Inicia-se assim o processo de constituição do que se tornaria a cidade de Anápolis. Em 1873 foi criada a Freguesia de Santana das Antas. De acordo com França (1974, p. 638): "[...] O seu território, formado com terras dos municípios de Meiaponte e Bonfim, foi constituido [sic] em 18 de junho de 1879, pela Lei 2.514. Passou a pertencer doravante ao Município de Meiaponte".

A outra explicação de acordo com Luz (2009, p. 176): "[...] corresponde à presença de condições naturais favoráveis no local onde se desenvolveu o sítio urbano de Anápolis".

A respeito dos aspectos naturais, Luz (2009, p. 176-177) exemplifica esses fatores: "[...] um relevo de ondulações suaves, perfazendo 54\% de seu território e com $43 \%$ de áreas planas; um clima tropical com temperaturas amenizadas pela altitude de, aproximadamente, 1.017 metros acima do nível do mar". A boa condição do meio natural propiciou a constituição e aglomeração de pessoas nesse local.

Os moradores utilizavam o córrego das Antas como referência local. De acordo com Luz (2009, p. 177), "[...] em meados do século XIX, em torno das paradas ou pousos, às margens de rios e córregos, surgiram edificações comerciais e moradias que, depois, transformaram-se em povoados e cidades, como no caso de Anápolis".

Em 1887, a região que se constituía como Freguesia, se eleva para Vila. De acordo com Moura (2012, p. 18), "[...] a lei 811 emancipa a região e cria a Vila de Santana das Antas; mas somente em 1892 a Vila se instala oficialmente, [...] A vila conta então com quase seis mil habitantes".

Em 1907, a vila é elevada a condição de cidade, com o nome Anápolis. Após esses acontecimentos históricos que elevaram a condição de um povoado para cidade, por meio de suas atividades locais, Anápolis primeiro, se desenvolve comercialmente, e $a$ posteriori industrialmente, ao se beneficiar das políticas de desenvolvimento implementadas pelo governo federal.

A construção de Brasília influenciou na implantação de uma ampla rede de rodovias que passaram a percorrer o território goiano. $\mathrm{O}$ município e, principalmente, a cidade de Anápolis está localizada estrategicamente no entroncamento das rodovias BR-060, BR-153 e BR-414 e se consolida na função de entreposto e base logística regional, também com a abertura de rodovias para a ligação de diferentes partes do país com a nova capital. Fato que consolida como alavanca para a economia regional (ver Mapa 02): 


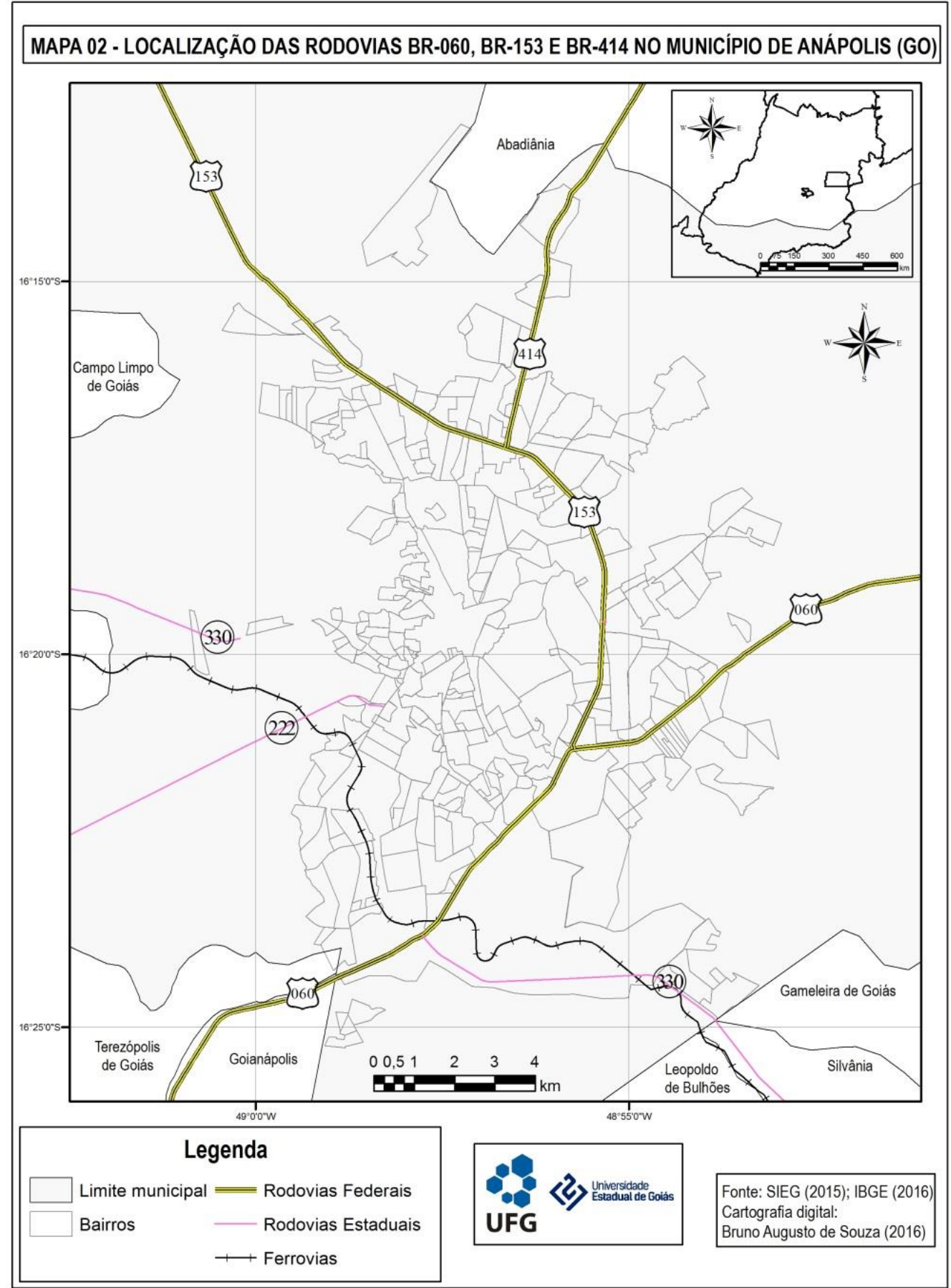

Os bairros, loteamentos, residenciais, etc., situados na parte nordeste de Anápolis se aglomeram ao redor dos bairros Jardim América $3^{\text {a }}$ Etapa e Recanto do Sol. O posicionamento dos mesmos em relação à área central da cidade estabeleceu a denominação sua referência, utilizada neste trabalho: área nordeste de Anápolis. Além dos referidos bairros compõem o aglomerado: Bairro Recanto do Sol, Jardim das Américas $3^{\text {a }}$ Etapa, Chácaras Vale das Antas, Sítios de Recreio Jardim Boa Vista, Vila Norte, Loteamento Residencial América, Parque Residencial das Flores, Sítios de Recreio Denise, Residencial Araguaia, 
Jardim dos Ipês, Residencial Portal do Cerrado, Residencial Vale do Sol, e Residencial Flor do Cerrado $1^{\text {a }}$ Etapa.

O terreno onde o Bairro Recanto do Sol foi criado, segundo dados do setor de cadastro imobiliário da Secretaria de Obras, Serviços Urbanos e Habitação da Prefeitura Municipal de Anápolis (2013), era propriedade de José de Deus e, sua aprovação inicial data de agosto de 1979, com a autorização de seu desmembramento por meio do Decreto $\mathrm{n}^{\circ} 2.810$ de 02 de março de 1983 sob responsabilidade da imobiliária Carmo Imóveis e Representações Ltda.. A área total do bairro é de $944.083,21 \mathrm{~m}^{2}$, composta por nove chácaras que totalizam $51.066,61 \mathrm{~m}^{2}$, logradouros totalizados em 192.346,90 m², área destinada a Prefeitura que era de $88.551,21 \mathrm{~m}^{2}$, área não loteada que seria de $30.550,00 \mathrm{~m}^{2}$ e outras áreas com 581.797,90 $\mathrm{m}^{2}$.

Enquanto, o bairro Jardim das Américas $3^{\mathrm{a}}$ Etapa era propriedade de Arthur Wesley Archibald e a procuradora responsável pelo loteamento foi a Imobiliária Epaminondas. O local fazia parte da Fazenda Capão do Pena, a aprovação do loteamento foi estabelecida pelo Decreto $\mathrm{n}^{\circ} 2.817$ de 09 de março de 1983, com área total de 452.004,74 m², representada por 620 lotes residenciais com total de 200.156,89 m², 30 lotes comerciais representados por $10.600,56 \mathrm{~m}^{2}$, área reservada ao lazer com $38.306,76 \mathrm{~m}^{2}$, área reservada aos edifícios públicos com $31.891,82 \mathrm{~m}^{2}$, ruas e avenidas que totalizavam $102.509,71 \mathrm{~m}^{2}$, e a faixa de domínio da BR-414 com $68.539 \mathrm{~m}^{2}$.

Havia loteamentos aprovados antes de 1983 na área nordeste de Anápolis, mas com características rurais, que eram correspondidos por Chácaras Vale das Antas que era propriedade de Geraldo Rosa, aprovada por meio do Decreto n ${ }^{\circ} 2.215$ em 19 de dezembro de 1979 e correspondia a 249 chácaras totalizando $1.352 .667,30 \mathrm{~m}^{2}$, duas áreas destinadas a PMA com $10.000 \mathrm{~m}^{2}$, e ainda 12 ruas e avenidas com 163.249,50 $\mathrm{m}^{2}$, que juntas dão uma área total de $1.525 .916,80 \mathrm{~m}^{2}$.

Outro loteamento com característica rural anterior a 1983, os Sítios de Recreio Jardim Boa Vista, que foi aprovado por meio da Portaria n 191 de 15 de agosto de 1978, com área total de $695.585,46 \mathrm{~m}^{2}$, que correspondiam a 110 chácaras com área total de $609.398,81$ $\mathrm{m}^{2}$, duas áreas da Prefeitura com $10.000 \mathrm{~m}^{2} \mathrm{e}$ sete ruas com 76.186,65 $\mathrm{m}^{2}$.

Após esse período da formação dos primeiros loteamentos na área nordeste de Anápolis, houve a aprovação de outros loteamentos, conforme destacamos a seguir.

A Vila Norte era de propriedade de João Florentino e sua mulher Delmira Florentino Mendes, por meio de Mardocheu Diniz Incorporadora e Empreendimentos Imobiliários Ltda. e do Decreto $\mathrm{n}^{\mathrm{o}} 2.759$ em 26 de novembro de 1982 que aprovou o 
loteamento. Essa área fazia parte da Fazenda Boa Vista, a gleba loteada se compreendia pela área total de $411.400,00 \mathrm{~m}^{2}$, que era composta por 829 lotes que totalizavam $256.489,24 \mathrm{~m}^{2}$, a reserva da área de lazer e praças era de $35.444,90 \mathrm{~m}^{2}$, para edifícios públicos $31.284,40 \mathrm{~m}^{2}$, e para o sistema viário compreendia a reserva de $88.181,46 \mathrm{~m}^{2}$.

O Loteamento Residencial América fazia parte da Fazenda Capão do Pena, pertencia aos proprietários William H. Naoum, George H. Naoum e Margareth Naoum. O loteamento foi aprovado por meio do Decreto $\mathrm{n}^{\circ} 2.826$ em 23 de março de 1983 e com remanejamento em julho de 1992, com área total de 467.410,00 $\mathrm{m}^{2}$, que dividiam em 832 lotes totalizando $277.980,45 \mathrm{~m}^{2}$, área de lazer e praças que correspondiam a $37.467,61 \mathrm{~m}^{2}$, área reservada a edifícios públicos que correspondia a $33.120,41 \mathrm{~m}^{2}$, e área reservada ao sistema viário com $118.841,53 \mathrm{~m}^{2}$.

O Parque Residencial das Flores também aprovado em 1983, precisamente por meio do Decreto no 2.831 em 25 de março de 1983, era de propriedade de João Florentino. Houve o remanejamento de quadras em 26 de dezembro de 1983 por meio do Decreto $\mathrm{n}^{\circ}$ 3.036, e também substituição de lotes caucionados por meio do Decreto $\mathrm{n}^{\circ} 4.680$ em 20 de janeiro de 1992.

Outro loteamento com características rurais da área nordeste de Anápolis, os Sítios de Recreio Denise tinha como proprietário Joaquim José Machado, fazia parte da Fazenda Boa Vista. Foi aprovado por meio do Decreto no 3.755 em 08 de maio de 1987, compreendia uma área total de $315.991,95 \mathrm{~m}^{2}$, com $278.383,13 \mathrm{~m}^{2}$ referentes a lotes, 15.402,64 m² para o sistema viário e 5.019,33 m² reservados à área pública.

Na década de 1990, ocorreu a aprovação de dois loteamentos, um deles é o Residencial Araguaia que pertencia ao Auto Posto Carreteiro Ltda., pertencente a uma gleba de terras situada na Fazenda Boa Vista, o empreendimento que realizou o loteamento foi o Lírios do Campo Empreendimentos Imobiliários Ltda., a aprovação se deu por meio do

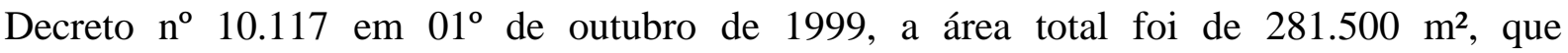
correspondia a 554 lotes totalizando 172.019,95 m², três áreas públicas referentes a 40.200,79 $\mathrm{m}^{2}$, o sistema viário com 53.011,85 m² e a área não edificante com $16.267,43 \mathrm{~m}^{2}$.

O outro loteamento aprovado na década de 1990 foi o Jardim dos Ipês que correspondia à área de propriedade de Belmiro Ribeiro Filho e Benigno Ribeiro, a representante do loteamento foi a Empresa Lírios do Campo Empreendimentos Imobiliários Ltda.. Sua aprovação se deu por meio do Decreto no 10.179 em 18 de novembro de 1999, a área total do loteamento foi de 529.746,59 $\mathrm{m}^{2}$, correspondendo a 987 lotes totalizando $313.595,30 \mathrm{~m}^{2}, 12$ unidades reservadas a área pública referentes ao total de $77.267,15 \mathrm{~m}^{2}$, 
122.258,69 $\mathrm{m}^{2}$ reservados ao sistema viário, e 16.625,45 $\mathrm{m}^{2}$ correspondentes a área não edificante.

A acelerada expansão dessa área se configura com a aprovação de três loteamentos nos primeiros anos do século XXI, o primeiro deles foi o Residencial Portal do Cerrado como antiga propriedade da Associação Educativa Evangélica e era uma área pertencente à Fazenda Boa Vista e Capão do Pena, os promotores imobiliários responsáveis pelo loteamento foram Confiança Empreendimentos Imobiliários Ltda., Catalão Empreendimentos Imobiliários Ltda. e RC Empreendimentos Imobiliários Ltda., a aprovação do loteamento se deu por meio do Decreto $\mathrm{n}^{\circ} 23.290$ em 03 de maio de 2007, a área total foi de $187.001 \mathrm{~m}^{2}$, que correspondia a 381 lotes residenciais totalizando $120.989,61 \mathrm{~m}^{2}$, $28.130,47 \mathrm{~m}^{2}$ reservados a áreas públicas, e o sistema viário que correspondia a $37.880,92 \mathrm{~m}^{2}$.

Outro loteamento aprovado na primeira década do século XXI foi o Residencial Vale do Sol por meio do Decreto n ${ }^{\circ} 2.515$ e 10.115 de 2008. E, por fim, o Residencial Flor do Cerrado $1^{\text {a }}$ Etapa que correspondia a uma gleba de terras, oriunda do desmembramento da Fazenda Boa Vista, por meio do Decreto no 33.617 em 26 de março de 2012, a área total correspondente ao loteamento foi de $578.155,70 \mathrm{~m}^{2}$, a área parcelada em lotes foi de 219.413,28 m² em 695 unidades, a área destinada ao sistema viário foi de $156.251,93 \mathrm{~m}^{2}$, a área destinada aos equipamentos públicos foi de $57.936,02 \mathrm{~m}^{2}$, e a área reservada para áreas verdes foi de $29.306,42 \mathrm{~m}^{2}$.

Ao reconhecer os loteamentos que compõem a área nordeste de Anápolis, pode-se analisar que o quantitativo maior de loteamentos aprovados foi na década de 1980, com seis aprovações, o que corresponde a quase $50 \%$ do total de loteamentos aprovados durante todo o tempo, em seguida, nos primeiros anos do século XXI foram aprovados três novos loteamentos, que demonstra a expansão recente dessa área.

No fim da década de 1970 e, principalmente, no início da década de 1980, a área nordeste de Anápolis iniciou o processo de povoamento. Atualmente essa área possui 13 bairros (ver Gráfico 01 e Mapa 03), entre loteamentos urbanos e loteamentos com características rurais, com três aprovações nas décadas iniciais do século XXI. 


\section{Gráfico 01 - Anos correspondentes à aprovação dos loteamentos da área nordeste}

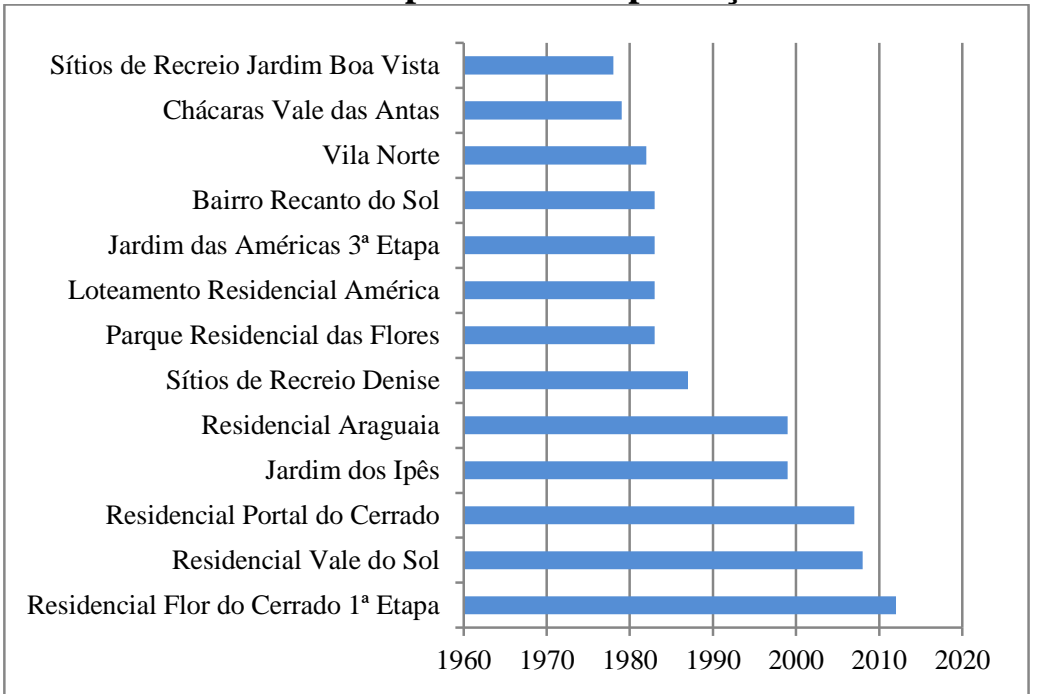

Fonte: Secretaria de Obras, Serviços Urbanos e Habitação (2013)

Organização: Janes Socorro da Luz (2013) 


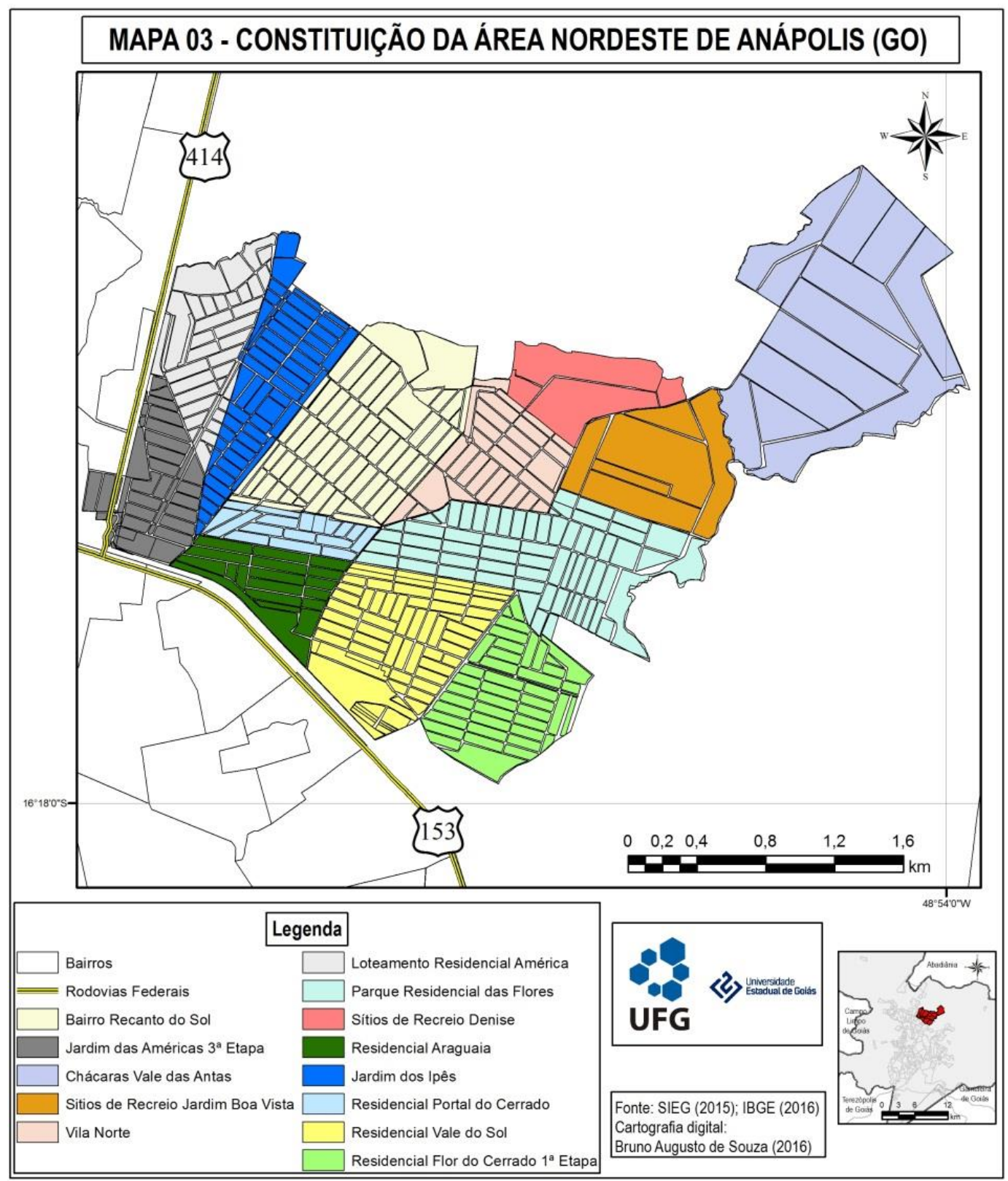

Para a conceituação dos eixos comerciais, Duarte (1974, p. 86) afirma que:

Tratam-se de ruas ou avenidas que, por constituírem importantes vias de acesso aos principais bairros, a circulação nelas concentrada provoca intenso movimento diário de pessoas que se desloca de um ponto a outro da cidade, atraindo para si lojas comerciais importantes.

Nas vias de circulação que constituem os eixos comerciais, as atividades estão presentes em grande extensão, propicia-se assim melhor comodidade para os que moram em seu entorno, gera-se capital e há a oferta de diversos serviços.

O espaço de circulação que os moradores da área nordeste de Anápolis dispõe é essencial para a boa localização desse local de expansão. Os eixos comerciais são: Av. Raimundo Carlos L. Silva que corta os bairros Jardim das Américas $3^{\text {a }}$ Etapa, Loteamento 
Residencial América e o Jardim dos Ipês; a Av. do Estado começa no bairro Recanto do Sol e também corta o Jardim dos Ipês, a Vila Norte e termina no Parque Residencial das Flores; a Av. 25 está no Parque Residencial das Flores; reconhecemos a Av. João Florentino como um eixo comercial embrionário, visto que a mesma está entre o Residencial Araguaia, o Residencial Portal do Cerrado, o Parque Residencial das Flores, o Residencial Vale do Sol e dá acesso ao Residencial Flor do Cerrado $1^{\text {a }}$ Etapa, esses dois últimos juntamente com o Residencial Portal do Cerrado são os loteamentos aprovados no século XXI, e formam a área de expansão da área nordeste de Anápolis, essa avenida possui diversos lotes vagos que propiciam a construção de imóveis específicos para o comércio, com expansão acelerada devido ao fato da área nordeste possuir inúmeras atividades.

Os eixos comerciais possuem o grande quantitativo das atividades e serviços, o local possui avenidas extensas como Av. Raimundo Carlos L. Silva, Av. do Estado, Av. 25 e Av. João Florentino.

Para Carlos (2007, p. 99), no que diz respeito à regulação ao espaço dos fluxos:

[...] o conteúdo da urbanização apareceria como momento determinado da reprodução em função das novas possibilidades/necessidades de realizar a acumulação. $O$ espaço, condição da produção do capital, ganha uma dimensão instrumental, enquanto que do ponto de vista do Estado - que regulariza os fluxos e controla a sociedade - aparece como instrumento de dominação estruturando a reprodução das relações sociais de produção. Nesta direção as mudanças no plano da sociedade se revelam enquanto mudanças espaciais, isto é, como transformações na prática sócio-espacial.

Para caracterizar o espaço na cidade, vale ressaltar que o mesmo está imbricado como o modo de dispersão para "a reprodução do econômico, o espaço é infraestrutura, concentração, mercado de trabalho e de matéria-prima em sua simultaneidade de relações e justaposições de esferas individuais" (CARLOS, 2011, p. 74).

Os eixos comerciais da área nordeste de Anápolis contam com inúmeras atividades terciárias para o uso de seus residentes (ver Mapa 04). No âmbito da configuração de atividades Centrais, Não-Centrais e da Zona Periférica do Centro (ZPC), pode-se destacar Souza (2009) que as separa de acordo com 17 variáveis que são: Comércio de Alimentos; Serviços da Saúde e Estética; Profissionais Liberais; Assistência Técnica; Serviços Automotivos; Cursos; Serviços Financeiros e Correios; Instituições; Móveis e Eletrodomésticos; Lazer; Serviços e Produtos Agropecuários; Imobiliárias; Vestuário; Materiais para Construção; Comércio Atacadista; Armarinhos e Papelaria; e Outras Atividades Centrais, Não-Centrais e ZPC. 


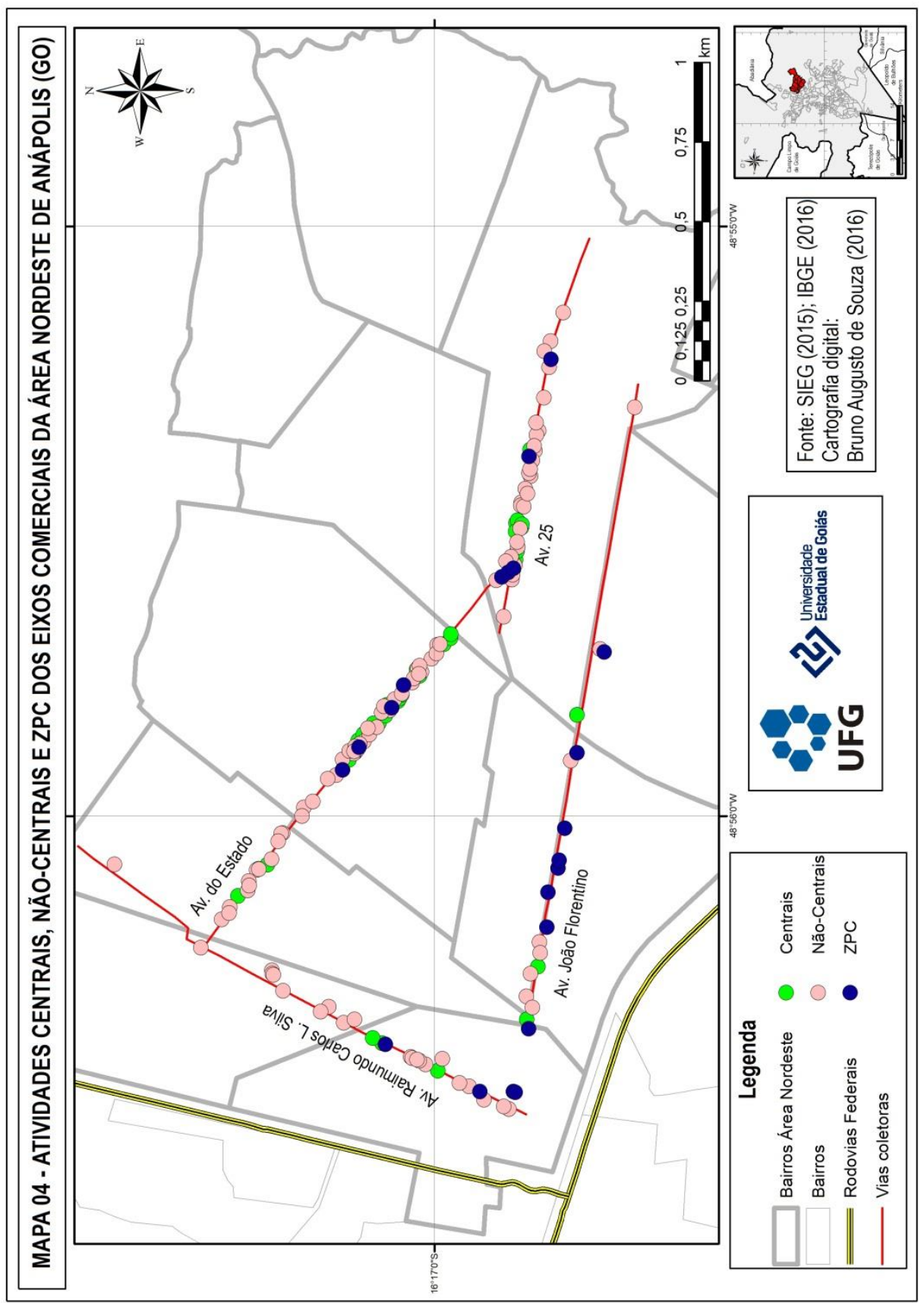

Na Av. Raimundo Carlos L. Silva há a presença de 04 igrejas, 04 bares, 03 mercearias, 03 sacolões, 02 farmácias, 01 auto elétrica, 01 lava jato, 01 loja de pneus, 01 clínica odontológica, 01 supermercado, 01 açougue, 01 borracharia, 01 papelaria, 01 loja de roupas, 01 lanchonete e 01 panificadora.

$\mathrm{Na}$ Av. do Estado, os moradores contam com 09 igrejas, 09 lojas de roupas, 07 bares, 06 cabeleireiros, 03 panificadoras, 03 açougues, 03 sorveterias, 03 lojas de calçados, 03 lanchonetes, 03 lan houses, 02 pizzarias, 02 lojas de moto peças, 02 mercearias, 02 ferragistas, 02 farmácias, 02 papelarias, 01 supermercado, 01 sacolão, 01 loja de móveis, 01 posto de saúde, 01 depósito de gás, 01 clínica odontológica e 01 serralheria. 
Já na Av. 25 há a presença de 06 igrejas, 06 bares, 05 lojas de roupas, 03 mercearias, 03 panificadoras, 02 açougues, 02 cabeleireiros, 02 restaurantes, 02 supermercados, 02 farmácias, 01 loja de móveis usados, 01 pet shop, 01 papelaria, 01 lotérica, 01 loja de calçados, 01 sacolão, 01 depósito de gás e 01 lava jato. Na Av. 25 há atividades importantes que diferenciam dos outros locais, como a presença do supermercado da rede Supervi, e também da rede de lojas Ducal Calçados.

Como se observa no Mapa 04, os eixos comerciais da área nordeste de Anápolis possuem quantitativo considerável de atividades Não-Centrais, configurando na área a presença não de uma nova centralidade, mas algo como uma centralidade embrionária que compõe principalmente atividades de consumo cotidiano e atividades de consumo frequente.

Com essas diversas atividades, a área nordeste de Anápolis é atrativa para a aquisição de novos lotes ou novas casas nos bairros que são os da expansão recente, o Residencial Portal do Cerrado, o Residencial Vale do Sol e o Residencial Flor do Cerrado $1^{\mathrm{a}}$ Etapa.

\section{Considerações Finais}

Este trabalho foi desenvolvido a partir de pressupostos para o entendimento da configuração do espaço urbano, pois, com o crescimento populacional, o perímetro urbano das cidades necessita se expandir para atender tal demanda.

Em Anápolis (GO) isso ocorreu por sua influência regional e relevância não só antigamente, mas até os dias atuais. Ao exercer a função de cidade média, Anápolis é uma das mais importantes cidades do estado de Goiás, sendo que seu desenvolvimento e atratividade se deram desde o início com as questões de comércio e foi se especializando ao longo do século XX. Visto que no final do século houve a implantação de atividades industriais relevantes para o crescimento econômico da cidade.

Ao compreender as questões de crescimento econômico, o crescimento Apopulacional vem para atender as demandas de mão de obra. Ao considerar essas questões, a infraestrutura e serviços necessários para a população estão presentes nos locais com quantitativo populacional para usufruí-las.

A constituição da área nordeste de Anápolis não é recente, data do final da década de 1970, passando por loteamentos aprovados em 1980 e 1990, bem como nos primeiros anos do século XXI. Com essa afirmação compreendemos o fator de não isolamento dessa área polarizada por bairros importantes como Jardim das Américas $3^{\text {a }}$ Etapa e Recanto do Sol. 
Além desses bairros, essa área está no entroncamento de duas importantes rodovias federais, que são as BR-153 e BR-414.

Com o aumento populacional, há a necessidade de aprovação de novos loteamentos na cidade e a área nordeste de Anápolis possuía locais ociosos como o Residencial Portal do Cerrado que compreendia em uma área vaga entre os bairros Recanto do Sol e Residencial Araguaia.

Ao realizar trabalhos de campo na área nordeste da cidade e analisar os dados das atividades presentes, compreendemos os subsídios para expansão acelerada, uma vez que existem inúmeras atividades e equipamentos urbanos para o benefício de novos moradores, pois, evitam-se longos deslocamentos e economia de tempo, proporcionando momentos de lazer com a família ou outros.

$\mathrm{Na}$ questão de descentralização, essa área compreende maior quantitativo de atividades Não-Centrais, afirmando seu papel de centralidade embrionária. Com a aprovação dos novos loteamentos e acelerada expansão, esse local pode futuramente constituir em uma nova centralidade na cidade de Anápolis.

\section{Referências Bibliográficas}

CARLOS, Ana Fani Alessandri. O espaço urbano: novos escritos sobre a cidade. São Paulo: Labur Edições, 2007, 123p.

A condição espacial. São Paulo: Contexto, 2011.

CORRÊA, Roberto Lobato. O Espaço Urbano. $3^{a}$ ed. São Paulo (SP): Ática, 1995.

Construindo o conceito de cidade média. In: SPOSITO, Maria Encarnação Beltrão

(org.). Cidades Médias: espaços em transição. 1 ed. São Paulo: Expressão Popular, 2007. pp. 23-33.

DUARTE, Haidine da Silva Barros. A cidade do Rio de Janeiro: descentralização das atividades terciárias. Os centros funcionais. In: Revista Brasileira de Geografia, Rio de Janeiro, 36 (1), p. 53-98, jan./mar., 1974.

FRANÇA, Maria de Sousa. A formação histórica de Anápolis e a sua área de influência regional. In: Simpósio Nacional dos Professores Universitários de História, 7., 1973, Belo Horizonte. Anais... São Paulo, v. 1, 1974, p. 635-664.

INSTITUTO BRASILEIRO DE GEOGRAFIA E ESTATÍSTICA. Censo demográfico de 2010 (IBGE Cidades). Disponível em <http://www.cidades.ibge.gov.br/xtras/home.php>. Acesso em maio-out./2013.

Estimativas da população de Anápolis (GO) em 2014. Disponível em $<$ http://www.cidades.ibge.gov.br/xtras/perfil.php?lang=\&codmun=520110\&search=goias|ana polis $>$. Acesso em out./2014.

LEFEBVRE, Henri. O direito à cidade. São Paulo: Centauro, 2001.

LUZ, Janes Socorro da. A (Re)Produção do Espaço de Anápolis/GO: a trajetória de uma cidade média entre duas metrópoles, 1970-2009. Tese (doutorado), Universidade Federal de Uberlândia, Programa de Pós-Graduação em Geografia, 2009. 
MOURA, Arnaldo Salustiano de. Cotidianos anapolinos. Dos anos 20 até 1970. Um olhar ao passado através dos documentos legislativos. - Goiânia: Kelps, 2012.

PREFEITURA MUNICIPAL DE ANÁPOLIS. Ficha cadastral de bairros. Secretaria de Obras, Serviços Urbanos e Habitação, 2013.

SANTOS, Milton. A Urbanização Brasileira. 2. ed. São Paulo: Hucitec, 1994.

SOUZA, Marcus Vinicius Mariano de. Cidades Médias e Novas Centralidades: análise dos subcentros e eixos comerciais em Uberlândia (MG). 2009. 236 f. Dissertação (Mestrado em Geografia) - Universidade Federal de Uberlândia, Uberlândia, 2009.

SPOSITO, Maria Encarnação Beltrão. "A produção do espaço urbano" em dez anos de GAsPERR: reflexão individual sobre uma trajetória coletiva. In: SPOSITO, Eliseu Savério (org.). Produção do espaço e redefinições regionais: A construção de uma temática. Presidente Prudente: UNESP/FCT/GAsPERR, 2005. pp. 85-115.

SPOSITO, Maria Encarnação Beltrão; ELIAS, Denise; SOARES, Beatriz Ribeiro; MAIA, Doralice Sátyro; GOMES, Edvânia Tôrres Aguiar. O estudo das cidades médias brasileiras: uma proposta metodológica. In: SPOSITO, Maria Encarnação Beltrão (org.). Cidades Médias: espaços em transição. 1 ed. São Paulo: Expressão Popular, 2007. pp. 35-67.

Recebido em outubro de 2014. Aceito em agosto de 2017. 